\title{
Turizmin Tarihî Kökenleri - I : Eski Çağlar - Mezopotamya Uygarlıkları
}

\section{Giriş}

Turizm, bilindiği gibi modern döneme ait bir kavram olarak ortaya çıktı. Buna bağlı olarak, turizmde tarihten söz edilirken veya doğrudan turizm tarihi araştırmalarının çoğunda, en fazla birkaç yüzyıla gidildiği görülür. Endüstri Devrimine uzanan bu tarihsel uzam, Antik Çağ'a kadar götürülse de çok fazla kapsamlı çalışmaya rastlanamamaktadır. Sosyal yaşamın bir parçası olarak turizmin tarihsel kapsamının büyük oranda son birkaç yüzyılı içermesinin, insanlık tarihi açısından aslında sorunlu bir yaklaşım olduğu söylenebilir. Birkaç milyon yıllık insanlık tarihi ve yaklaşık 300 bin yıllık Sapiens tarihi için son beş on yıllık geçmişi incelemenin bile yeterli görülmediği bir anlayış içinde (Şenel 2006; Harari 2015) turizmin tarihsel uzamindaki kısıtlık daha da sorunlu hale gelmektedir.

Uygar toplumların daha iyi kavranabilmesi için ilkel insanların yaşamının kavranması, arada sıçramalar, kesintiler olsa dahi zorunludur. Nitekim, bu sıçramalar, kesintiler ve süreklilikler, kültürel evrim sürecinin daha iyi izlenmesini de sağlar (Şenel 2006). Barnard'a (2016) göre ise insanlık tarihinde kesin ayrımlardan söz etmek yerine, "kültürel değişim" olarak ele almak daha uygundur. Çoğu antropoloğa, göre insanlık tarihindeki kırılma noktaları her ne kadar devrimsel nitelikli olabilse de gerçekte bazı durumlar bir "geçiş"tir. İnsanlar yaşadıkları dünyayı daha iyi tanıyı öğrendikçe bunu yaşamına uyarlamış, bilişsel ve kültürel gelişim devam etmiştir.

Eski çağlarda, pek çok topluluk ve uygarlık, dünyanın merkezine kendini koyma eğilimini göstermiş, inanç ve düşünce sistemini bu temelde geliş- tirmeye yönelmiştir. Bu topluluklar daha sonra, komşularını ve yaşadıkları dünyayı tanımaya ve ekonomilerini geliştirmek için ticaret yapmaya başlamıştır. Antik Çağ'da Yunan'la başlayan döneme kadar çok büyük seyahat hareketlerinden söz etmek zor olsa da ilk insanlardan itibaren turizmin ilk temellerinin atılmaya başladığı, günümüzde devam eden bazı motivasyonlarla ilk yer değiştirme davranışlarına ve yolculuklara çıkıldığı görülmektedir (Rabotic 2014). Bu çalışmada, insanlık tarihine dair bilinen ilk hareketler ve seyahat olgusuna en fazla rastlanan Mezopotamya uygarlıklarındaki durum ele alınmaktadır. Bir başka deyişle, daha biçimsel ve yoğun seyahatlerin ortaya çıktığı Antik Çă̆'dan önce, turizm olgusunu besleyen tarihî kökenler irdelenmektedir.

\section{ETIMOLOJIK KÖKENLER}

Her ne kadar Grand Tour ile modern turizmin adımları atılmış olsa da günümüzdeki anlamıyla turizmin 19. yüzyıl ortalarında ve somut olarak da 1841 yılında Thomas Cook'un paket tur organizasyonu ile başladığ 1 kabul edilir. Ancak bir sosyal olgu olarak, turizme benzer hareketlerin geçmişi, insanlık tarihi kadar eskidir. Turizmin tarihî kökenlerine giderken kavramlar arası geçiş yapmak gerekir. Modern öncesi döneme bakıldığında, turizmin yerini seyahat kavramı alır. Seyahat ve turizm birbirinden ayrilamayan kavramlarken (Vuconic 2012) ve her ikisi de, başlanan yere geri dönmeyi içerir. Turizm her ne kadar son iki yüzyıllık bir olguysa, seyahat olgusu, kendisini daha çok tarım ve yerleşik hayatta gösterecek olan üretken ekonomilere geçişle birlikte 
(Diaz-Andreu 2019) son 10-12 bin yıl içinde ortaya çıktı. Seyahat olgusunun kökenlerine gidildiğinde ise yer değiştirme ve göçü kapsayan hareketlilik karşımıza çıkar.

Turizmin tarihsel kökenini incelerken, sözcügün etimolojik kökenine değinmek, sosyal alg1 ve dil arasındaki ilişkiyi yansıtması açısından yararlıdır. Mevcut bilgilere göre, turizm sözcügü İngilizce'de (tourism) ilk kez 1811'de Oxford İngilizce Sözlüğü'nde kullanıldı. Sözcüğün kökenini oluşturan tur (tour) ise 1300'lerde eski Fransızca'da "dönmek, bir turu tamamlamak" anlamında kullanılırken, bu sözcüğün de kökeni benzer anlamda kullanılan Latince tornare sözcügünden gelmektedir. Tur sözcügüüün 1640'larda, "tamamlanmış bir gezi" yi ifade etmek için kullanılması (https://www.etymonline.com/word/tour), ilerde turizm kavramına dönüşmesinin bir işareti olarak düşünülebilir. 1500'lerden önce Avrupa dillerinde turizm, turist gibi sözcükler yoktur. Ancak seyahat (travel) ve seyahat etme, yola çıkma (journeying) gibi sözcükler kullanılıyordu (Leiper 1983). Seyahat (travel) sözcügü ise Latince travail (zorluklara katlanmak) sözcügünden türemiştir. Tarih boyunca zorluklarla eşdeğer bir olay olarak görülen seyahatin, dilde de bunu ifade eder biçimde gelişmesi bir algının yansıması olarak dikkate değerdir. Turizm sözcüğü Türkçe'ye yabancı kökenli olarak yerleşti. Seyahat ise Arapça'da gezi sözcügünden gelir. Turizm sözcügünün etimolojik gelişimine bakıldığında, günümüzdeki anlamda, keyif, zevk, dinlenme, iş, eğitim vb. gibi bir amacı içermediği, buna karşın en özlü ifadeyle bir yerden bir yere gitme düşüncesine dayandığı görülmektedir (McCabe 2009). Nihâ̂ varış yeri ise seyahatin sonunda dönülen ikametgâhtır.

\section{ESKI ÇAĞLAR'DA INSAN HAREKETLILIĞi}

Turizmin insanlık tarihi içinde incelenmesine antropoloji disiplininden önemli katkılar vermiştir. Antropolojik bakış açısına göre turizm, her türlü insan topluluğunda mevcut olup araştırılabilecek bir konudur. Sosyal bir olgu olarak turizm en basit anlamda, özünde turist olarak adlandırılan bireyin bulunduğu, yer değiștirme ve kültürel karşılaşmayı ifade eder. Bu açıdan bakıl- dığında ilkel insanlardan günümüz insanlarına kadar farklı toplum düzeylerinde ele alınabilecek bir olgudur. Antropoloji disiplini turizme oldukça değerli katkılarda bulunmakla birlikte, çoğunlukla turizmin kültürel etkileşim, ev sahibi-misafir ilişkileri bağlamında ele alınmasından (Nash 1981) daha geniş bir perspektife ihtiyaç olduğu söylenebilir.

Turizmle ilgili çalışmalarda karşılaşılan kapsam farklılıklarının bir nedeni, henüz üzerinde uzlaşılmış bir turizm teorisinden söz edilememesidir. Turizmin merkezinde "turist" olduğu düşüncesiyle, turist deneyimlerine dayanan tipoloji çalışmaların, turizm teorisi için yeterli olmadığ 1 ve turizm kavramını daralttığı ileri sürülmektedir (McCabe 2009). Buna karşın, insanların (ve ayrıca eşyaların, nesnelerin, sermayenin, bilginin) dünya üzerinde hareket etmesini ifade eden hareketlilik kavramı, turizmi daha geniş bir boyuta doğru yönlendirmektedir (Hannam 2009) ve tarihsel izleği daha mümkün hale getirmektedir. Bu açıdan bakıldığında hareketlilik, insanlık tarihi boyunca sosyal yaşamın ayrılmaz bir parçası olmuştur.

Modern turizm, insanlık tarihinin henüz çok k1sa sayılabilecek bir zamanında ortaya çıkmasına karşın, insanlar çok eski zamanlardan beri hareketlilik halindeydi. İnsanoğlunun yaklaşık iki buçuk milyon yıldır dünyada olduğu, günümüz insanı Homo Sapiens'in ise yaklaşı 300-350 bin yıldır yeryüzünde olduğu bilinmektedir. Eldeki bilgilere göre Sapiens insanı, ilk ortaya çıktıkları bölge olan Afrika'da devam eden uzun yaşamlarının ardından, yaklaşık 100 bin yıl önce yavaş yavaş dünyaya yayılmaya başladılar. Kuzeye doğru ilerleyen insanlar muhtemelen önce Avrupa'ya, yaklaşık 65 bin yıl önce Çin'e ve yaklaşık 50 bin yıl önce ise Avustralya'ya, M.Ö. 8000 yıllarında ise Bering Boğazı'ndan Amerika kıtasına ulaştılar. Büyük Okyanus'taki Hawaii ve Yeni Zelanda adalarının keşfi ise M.Ö.1000'li yıllardadır. Doğudaki keşiflerle ilgili detaylı verilere rastlanmasa da Batıdaki keşiflerle ilgili çok sayıda mit, efsane, arkeolojik kalıntı ve metinlere ulaşılabilmektedir. Buzullar sayesinde kıtalar arasında daha kolay geçiş yapan insanlar buzulların erimesiyle tekrar binlerce yıl sonra karşılaştılar (Şenel 2006; McNeill 2019). Doğada pek fazla 
iz bırakmadan binlerce yıl yaşayan bu insanların hareketliliğinin en temel nedeni hayatta kalmaktı. Hayatta kalmak için ise temel motivasyon yiyecek bulmaktı. Diğer yandan, Sapiens insanında daha fazla görüldüğü gibi insanlarda, bulunduğu bölgenin ötesini merak etme duygusu da hep var oldu. Bütün bunlar turizm sayılmasa da mekân değiştirme veya çıkılan yere geri dönmeye daya1 döngüsel türde hareketliliğin insan yaşamında hep var olduğunu göstermektedir (Diaz-Andreu 2019). Günümüzde bu hareketliliğin modern anlamda turizm biçimine dönüştüğünü söylemek mümkündür.

Mevcut bilgilere göre, arkaik Sapiens, Neandartel ve Denisovalılar gibi diğer insan türleri binlerce yıl boyunca doğada pek fazla iz bırakmadan yaşadılar. İnsanlık tarihinde devam eden başlıca kırılma noktalarından biri yaklaşık 70 bin ile 40 bin yıl önceki dönemde insanın bilişsel olarak hızla gelişmesi ve "kültür" üretmeye başlamasıdır. Bu dönemde insanlar ateşi günlük ve kontrollü olarak kullanmaktaydı, din benzeri ritüelleri gerçekleştirmeye ve sanatın ilk örnekleri kabul edilebilecek eserler üretmeye başladılar. Basit kayık yaparak sıcak tutacak kıyafetler de ürettiler. Dil ve konuşma becerileri bu dönemde hızla gelişti (Watson 2017). Bilişsel devrim olarak adlandırılan bu dönemde insanlar, Afrika'dan çıarak dünyanın farklı bölgelerine yayılmaya başladılar. Temel olarak yiyecek bulma motivasyonuyla yeni yerler aramaya yönelseler de doğal felaketler gibi zorunlu nedenlerle de yola koyuluyorlardı. Bu insanlar için sürekli olarak yolda olmak doğal bir yaşam biçimiydi. Ancak avcı toplayıcı topluluklarda belli bir bölgede yerleşik hayatı sürdürmek ve bu bölge sınırları içinde hareket etmek elbette devam etmiştir. Avcı toplayıcıların her zaman zor ve çileli bir yaşamları olduğu da bir yanılgıdır. Bu topluluklar, yaşamlarını idame ettirecek kadar faaliyette bulunup, boş zamana da değer vermişlerdir (Barnard 2016). Bu gerçeklik de boş zaman olgusunun modern döneme ait olduğu görüşünü yeniden düşünmeyi gerektirir.

Doğayı çok iyi tanıyan avcı toplayıcılar, doğayı gözlemleyerek, hayatta kalma güdüsüyle bilgi ve becerilerini sürekli olarak geliştirdiler. Bu nedenle, yaşadıkları dünyayı çoğunlukla zorunlu görü- nen nedenlerle, bazen de merak duygusuyla tanımaya çalıştılar. Avcı toplayıcıların yeryüzündeki yolculuklarına dair en belirgin kanitlar, yolculukları sırasında farklı bölgelere ait olan ve beraberlerinde taşıdıkları nesnelerdir (Diaz-Andreu 2019). Bu da beraberinde kültür ve dil gelişimini getirdi. Paleolitik Çağ adı verilen bu çağ, insanlığın en uzun dönemidir. Bu dönemin sonlarına doğru, çağdaş türde Homo Sapiens insanına ait önemli kalıntılara Güney Fransa'daki Cro Magnon Mağarası'nda rastlanır. Otuz bin yıldan daha fazla bir süre önce, bu mağarada Atlas Okyanusu kıyılarına ait deniz kabukları bulunmuştur. Benzer şekilde, Nördlingen yakınlarındaki mağaralarda Akdeniz'den getirilen Columella Rustica kabukları, Girit ve Misır'da mezarlarda Avrupa kaynaklı kehribar bulunması, ilk seyahatlere işaret ederken, bu seyahatlerde değerli kaynakların taşındığını da göstermektedir (Löschburg 1998). Bu şekilde bir değişim ekonomisinin de başlamış olması muhtemeldir.

\section{MEZOPOTAMYA UYGARLIKLARINDA SEYAHAT}

Taş Çağı' nın sonuncusu olan Neolitik dönemde (Cilalı Taş Dönemi, M.Ö. 10.000-5500) tarım ve hayvanın evcilleştirilmesi ile yerleşik hayat gelişmeye başlandı. Dinsel ritüellerin ise tarımdan önce başladığı bilinmektedir. Mezopotamya, Neolitik Dönemin merkezidir. Tarihin ilk uygarlık merkezi olan Mezopotamya, Güney Anadolu'dan doğan Dicle ve Firat nehirleri arasından Basra (İran) Körfezi'ne inen ve büyük bölümünü Irak'in oluşturduğu bölgeyi içerir. Uygarlık gelişimi açısından bakıldığında bu bölge, Akdeniz' in doğu kıyılarında bulunan Kuzey Mısır'dan başlayarak, Suriye, Lübnan ve İsrail'den, Güneydoğu Anadolu'ya çıan, Irak'tan Basra Körfezi'ne inen bir hilâle benzetilerek Verimli Hilâl olarak adlandırılır. Bilinen en eski uygarlık, M.Ö. 7000 yılına tarihlenen yerleşim yerleri ile Konya'da yer alan Çatalhöyük'tür. Burada daha basit bir uygarlık bulunmasına karşın, ilk olarak Sümerler'de daha gelişmiş bir uygarlığa rastlanır. M.Ö. dördüncü binyıldan itibaren Sümerlerin yaşamına dair çeşitli kanıtlara ulaşılabilmektedir. Sümerler yazl, takvim sistemi, tekerlekli araba, yelkenli gibi önemli buluşlara imza attılar (McNeill 2019). 
Doğu Akdeniz kıyıları, Güney Doğu Anadolu Yerleşim yerleri arasında değerli kaynakların değişimi ile seyahatler de giderek arttı. Böylece, seyahat nedenlerine ticaret eklendi. Bu dönemde sıklıkla alet yapımında kullanılan obsidyen uzun ticaret yollarının ortaya çıkmasını sağlayan ilk ürün oldu. Bunu izleyen diğer değerli kaynaklar bakır, deniz kabukları ve çakmak taşıdı ı (Aydın 2015). Avcı toplayıcılarda olduğu gibi yemek ve değerli kaynaklara ulaşmak ve son dönemlerine doğru, basit değişim ekonomisinin izlerinde de görüldüğü gibi, ticaret amaçlı seyahatler Mezopotamya, daha sonrasinda ise Antik Yunan ve Roma Dönemi'nde de başlıca seyahat amacını oluşturmuştur. Buna ek olarak, her uygarlık kendine özgü farklı seyahat amaçlarını da geliştirmeye devam edecektir.

Yerleşik hayatla birlikte nüfus hızla artarken, Mezopotamya'dan İran, Hindistan, Pakistan, Güney Arabistan ve İndus Vadisi'ne doğru ticaret yollarından oluşan bir ağ ortaya çıktı. Ulaşımda daha çok deniz ve akarsulardan yararlanılıyordu. Bütün bu gelişmeler, toplumsal organizasyonun gelişimini hızlandırd1, devletler, zengin sınıf ve köleler gibi toplumsal tabakalar ortaya çıtı. Devletler ve şehirler arasında ticaretin gelişmesi, kültürel karşılaşmalar ve etkileşimleri arttırdı. Bu etkileşimlerle, bilinen dünyayı merak etme ve keşif duygusu da arttı. Bazı devletler yeni coğrafya ve kaynaklar için keşfe çıkarken, merak duygusuyla ilk seyyahlar da yollara düşmeye başladı. Taşımacılık ve seyahatler oldukça meşakkatliydi. Kara yolundan yararlanıldığı kadar, daha verimli ulaşım imkânı sağladığından, deniz ve nehir yollarından da yararlanılıyordu. Denizcilikte en başarılı toplumun M.Ö. 2000 yıllarında ortaya çıkan Fenikeliler olduğu ileri sürülür. M.Ö. 1000 yıllarında, Suriye, Kuzey Lübnan ve Tunus gibi önemli yerlere hakim olan Fenikeliler'in, Afrika'nın güney ucunu keşfederek kıtanın çevresini dolaştığı düşünülmektedir (Aughton 2019). Heredotus da Tarih kitabında bu keşiften bahseder. Tarih boyunca ilk insanlardan, Fenikeliler'e ve Müslüman denizcilere kadar pek çok toplum dünyayı keşfe çıkmış olsa da Şengör (2017) gerçek anlamda keşfin, kayıt tutmak ve keşfedilen yerleri gözlem ve bilgi toplama ile anlam kazandığını ileri sürer.
Sümerler' in buluşlarından etkilenen ve karşılıklı ticaret yapan bir başka uygarlık Mısırlılar'dır. M.Ö. 3000'li yıllardan itibaren inşa edilen M1sır Piramitleri daha o dönemden itibaren yakın bölgeden ziyaretçileri çekmeye başladı. Tarihsel incelemeler insanoğlunun pek değişmeyen bazı kabul görmeyen dürtülerinin geçmişte de var olduğunu göstermektedir. Bunların başında gelen ve günümüzde de devam eden bir davranış olarak, arkeolojik kalıntılara ve anıtlara isim vb. kazıma çabasına, hemen o dönemde Mısır Piramitleri'nin ziyaretçilerinde de rastlanır. Örneğin, M.Ö. 1261'de Ptah-Emwe adlı bir ziyaretçi Piramitleri ziyaret ettiği bilgisini piramide kazımiştır (Diaz-Andreu 2019). Diğer yandan ziyaret edilen yerlerden hatıra veya hediyelik götürmek isteyenler için Piramitler gibi çekim merkezlerinde bu amaçla ürün satışına da rastlanır (Casson 1985).

Turizm tarihi açısından Eski Mısır'da karşılaşılan bir başka önemli olay, ilk seyahatname örneğinin verilmesidir. İlk kadın firavun kabul edilen Kraliçe Hatçepsut M.Ö. 1480'in ilk yıllarında Afrika'nın doğusunda yer alan ve kutsal ülke olarak bilinen Punt ülkesini (bugünkü Somali civarı) ziyaret etti. Kraliçe, iki ülke arasında ticaret ilişkilerini geliştirmeyi amaçliyordu. Punt ülkesinden ilk kez görülen değerli bitkiler, ahşaplar, güzel kokulu reçine gibi çeşitli kıymetli eşyaları alarak kafilesiyle Misır'a geri döndü. Bu seyahat, Punt rölyefleri adlı kabartmalara nakşedildi. Bu kabartmalar bilinen ilk seyahat anlatısı kabul edilir (Löschburg 1998; Dallı 2020).

M.Ö. üçüncü binyılın ortalarından itibaren, Mezopotamya'da sağlık amacıyla şifacıların bulunduğu yerlere seyahatlere rastlamak mümkündür. Benzer biçimde, farklı iklim koşullarından terapi amacıyla yararlanma düşüncesi de yer almaktaydi. Endüstri Devrimi sonrasina kadar, sağlık amaçlı seyahatler çoğunlukla üst sınıflara özgü bir olay olarak devam etti (Kevan 1993).

Mezopotamya'da M.Ö. 3000 bin yılından itibaren başlayan seyahatler, Nil, Fırat ve Dicle nehirleri üzerinde ulaşım ve kıyılarına yönelik hareketler ile Suriye ve Filistin bölgelerinde yoğunlaş1yordu. Gemiciliğin gelişmesiyle Akdeniz, Kızıldeniz ve İran Körfezi'ndeki hareketlilik de arttı. 
Misır'da Nil nehri ve bu nehre açılan kanallar ulaşımı oldukça kolaylaştırdı. Dicle ve Fırat, Nil kadar kullanışlı değildi. M.Ö. 3000'den itibaren yine Sümerler'in icat ettiği tekerlek sayesinde tekerlekli araçlarla taşımacılık da gelişmeye başladı. M.Ö. 2300'den itibaren ise atın taşımacılıkta kullanılmaya başlamasıyla iki tekerlekli arabalar geliştirildi. Bunlardan daha sağlam olan tunç arabaların geliştirilmesiyle, Mezopotamya'dan önce İndus Vadisi, oradan Ganj ve Çin'e kadar uzanacak olan ticaret yollarının temellerinin atıldığı söylenebilir. Eski Dünya uygarlıklarından en sonuncusu sayılan Çin, yaklaşık M.Ö. 1400 yıllarında gelişmeye başladı (Şenel 2006). Tarih boyunca bu ticaret yolları sadece malların değil, kültür, din, bilim ve teknolojinin taşınacağı, çok yönlü etkileşimlerin kanalı olma rolünü üstlenecektir. Ticaret yollarının aynı zamanda, merak ve keşif güdüsüyle, büyük tehlikeleri göze almayı gerektiren seyahatler için çok sayıda seyyahı da cesaretlendireceği söylenebilir.

Heredotus'un verdiği bilgilere göre, Eski Mısır'da ayrıca, yılın belirli zamanlarında, Nil Nehri'nde, en ünlüsü Bubastis olan festivaller geniş katılımlarla gerçekleşiyordu. Yaklaşık M.Ö. 1500'lü yıllardan itibaren Misırlılar'da keyif ve merak amaçlı seyahatler de artmaya başlar (Casson 1985). Mezopotamya uygarlıklarında, en yakın hukuki düzenlemeler, Babil'in güçlü lideri Hammurabi (M.Ö. 1792-1750) ile başlamıştır. Örneğin, hanların işletilmesi ve içecekte sahtecilik yapılmasına karşı, "kısasa kısas" türündeki sert yaptırımlar belirlenmiş̧tir.

Mezopotamya'dan günümüze ulaşmış bir konaklama mekânı bulunmasa da Girit'te M.Ö.1500'lü yıllardan kalan bir yapı bulunmaktadır (Casson 1985). Tarih boyunca başta Roma, Moğollar ve Türkler'de görüleceği gibi devletler, askerî ve ticarî amaçlı güzergâhlar üzerinde, konaklama, posta ulaştırma, bazen de askerî amaçlı hanlar inşa ediyordu ve bu hanların ilk örnekleri Eski Misır ve Miken uygarlıklarında bulunmaktayd. Bu hanlar, hem resmî hem de resmî olmayan ziyaretçilerin konaklama ve yiyecek-içecek imkânlarını karşılıyordu. Mısır'da Yeni Krallık döneminde, firavunlar yirmi bin askerden oluşan ordular toplayabiliyordu. Bu durum, büyük bir lojistik ve organizasyon becerisi gerektirmekteydi (Watson 2017). Benzer biçimde, Mısır Piramitleri ve Göbeklitepe'deki yapıların inşası gibi çok sayıda insanın ulaşım, barınma ve temel ihtiyaçlarının tedarik edilmesi ve karşılanması ihtiyacı, geniş organizasyon becerilerinin erken dönemlerden itibaren gelişmeye başladığını göstermektedir.

\section{ILK SEYAHAT ARKETIPI: KAHRAMANIN YOLCULUĞU}

Kültürel gelişim, dil ve ilk inanç sistemlerinin en somut göstergesi olan mitler, yaşanan ve hissedilen dünyaya dair bütün bir açıklama sunduğu ölçüde, nesilden nesle aktarılan bilgi olmuştur. Bu bilgi, nesilden nesle aktarılarak, insanlara dünya, yaşam ve inanç sistemleriyle ilgili rehber görevi gördü. İnsanların ilk kültürel birikimlerinin örnekleri olarak mitlere bakıldığında sıkça seyahat olgusundan söz edildiği görülür. Bilindiği gibi, ilk yazılı mit olan ve M.Ö. 2000'lerde yazıya geçirilen, Sümerler'e ait Gılgamış Destanı, Ur şehrinin güçlü kralı Gılgamış'ın kahramanlık, ölümsüzlük ve gençlik arayışıyla acıktığı seyahatleri anlatması açısından büyük önem taşır. Campbell (2010), mitlerde ve daha sonra günümüze kadar devam eden pek çok anlatıda sıkça başvurulan bir kahramanın yolculuğunun bir arketip (ilk örnek) olarak sonraki mitler, seyahatler, öykülere yansımasından söz eder. Bu etkinin günümüzde de devam ettiği rahatlıkla söylenebilir.

Kahramanın yolculuğu, bir insanın arayış, keşif, deneyim kazanma, öğrenme, zorluklarla mücadele etme, yeni veya benzersiz olaylar, yerler, nesneler veya insanlar görme gibi amaçlarla seyahate çımasına dayalı bir modeldir. İlkel mitolojinin ardından, ilk uygarlıkların hemen hepsinde gelişmiş mitlere rastlanır. Kahramanın yolculuğu arketipi ise pek çok mitte işlenen önemli bir olay örgüsü sunar. Bu olay örgüsüne göre, yolculuk üç aşamadan oluşur (Campbell 2010):

- Ayrılma: Bir çağrıya (macera, arayış, kaçış, başarma, öğrenme, kahramanlık, keşfetme vb.) yönelme. Bu aşamada seyahat olağanüstü yardımcılar veya bir olayla başlar. Seyahat çoğunlukla bilinmeyene yöneliktir. 
- Gelişme: Bireyde aşkınlık uyandıran bir veya birkaç olay, kişi, durum vb. ile karşılaşma.

- Geri dönüş: Seyahatte kendisini dönüştürücü bir deneyim yaşamış olan birey, çıtı̆̆g yere geri döner. Çoğu zaman bu deneyimini geri döndüğü halkla veya çevresiyle paylaşır. Deneyimin sonucunda bazen ödül vb. somut karşılığ olsa da çoğunlukla soyut ve manevî niteliklidir.

Campell'in (2010) ele aldığı biçimiyle bu monomitte, seyahat tam bir döngünün tamamlanmasına dayanır. Yola çıkan kişi bazen bu yolculuğu yarıda kesebilir, bazen de dizi halinde devam eden zorlayıcılarla daha fazla mücadele etmekten kaçınarak geri dönebilir.

Kahramanın yolculuğu modeline göre, kişi bu seyahate belirli bir amaçla çıkabileceği gibi, fark1 amaçla çıktığ ${ }_{1}$ bir seyahatte de eşsiz bir deneyim elde ederek kahramanlık, bilgelik gibi kendini gerçekleştirme düzeyine erişebilir. Böylece, mitlerle başlamış olan, "önemli bir deneyim kazanmak için seyahate çıkma düşüncesi" Büyük Coğrafî Keşifler kadar çığır açıcı olmanın yanı sıra, günümüze kadar devam eden bir düşüncenin temelini oluşturur. Bu durum, aslında pek çok araştırmacının da vurguladığı gibi (Campbell 2010; Harari 2015), mitlerin günümüzde de biçim değiştirerek devam etmesinin de bir göstergesidir. Bugün özellikle, dönüştürücü turizm kavramında da vurgulandığı gibi, bireyler doğrudan dönüşüm niyetiyle seyahate çıkarak veya bu niyeti gütmeksizin de olsa çıkılan bir seyahat aracılığı ile bireysel dönüşüm yaşayabilmektedir (Robledo ve Batle 2017). Mistik ve ruhanî amaçlardan, wellness, gönüllü faaliyetlere katılmak ve eğitime kadar pek çok farklı amaçlarla çıkılan seyahatlerde asıl amaç kahramanın yolculuğunda olduğu gibi, bir şeyi aşmak, başarmak, kendini keşfetmek, zorluklarla mücadele, erginlenme (örneğin, gençlerin keşif veya gönüllü turizm hareketleri) gibi farklı deneyimlerle bireysel dönüşümü destekleyebilmektedir. Günümüzde bu seyahatlere daha fazla başvurulmasının nedeni, rutin yaşamdan uzaklaşırken aynı zamanda bireysel dönüşüm yaşama arzusudur (Kirillova, Lehto ve Cai 2017).

\section{SONUÇ}

İnsanlık tarihine dair mevcut bilgilere bakıld1- ğında, eski çağlardan Antik Çağ'a kadar olan dönemde, binlerce yıl boyunca inanlar başlıca hayatta kalmak ve yiyecek bulmak amacıyla coğrafî hareketliliğe başlamıştır. Neolitik Dönem'e doğru bu hareketliliğe merak ve ticaret de eklenirken, yerleşik hayat ve ilk uygarlıkların kurulduğu bu dönemde geçmişten gelen nedenlerin yanında ticaret giderek ağırlık kazanmıştır. Genel olarak bakıldığında, insanlık tarihinin en uzun dönemini oluşturan Antik Çağ öncesi dönemdeki hareketlilik olgusunun ulaşım araçları gibi teknolojik gelişmeler ve kültürel etkileşimlerle birlikte dönüştüğü görülür. Bu dönemdeki seyahatlerin daha çok zorunlu gerekçelerle, askerî, ticarî ve Fenikeliler'in deniz seyahatleri gibi çok az da olsa keşif amacıyla olduğu söylenebilir. Antik Çağ öncesi dönem esas olarak, Yunan'da hızla artacak ve çeşitlenecek olan seyahatlerin altyapısını hazırlayan "bilinen dünya" ya dair temel bilgilerin oluşturulmasını sağlamıştır.

\section{KAYNAKÇA}

Aughton, P. (2019). Dünyanın Çehresini Değiştiren Seyahatler. İstanbul: İş Bankası Kültür Yayınları.

Aydın, H. (2015). Dünyanın Oluşumu ve Tarih Öncesi Çağlar. İçinde; T. Sivas, (Ed.) Uygarlık Tarihi, (ss. 2-25). Eskişehir: Anadolu Üniversitesi Yayınları.

Barnard, A. (2016). Simgesel Düşüncenin Doğuşu. İstanbul: Boğaziçi Üniversitesi Yayınları.

Campbell, J. (2010). Kahramanın Sonsuz Yolculuğu. İstanbul: Kabalcı Yayınları.

Casson, L. (1985). Travel in the Ancient World. Baltimore: The Johns Hopkins University Press.

Dallı, İ. (2020). Saba Melikesi mi Hatshepsut mu?, https://bilimteknik.tubitak.gov.tr/system/files/biltek_arsiv/S-127-18. pdf. Erişim Tarihi: 12 Ağustos 2020.

Diaz-Andreu, M. (2019). A History of Archeological Tourism. Barselona: Springer.

Hannam, K. (2009). The End of Tourism? Nomadology and the Mobilities Paradigm. İçinde; J. Tribe (Ed.). Philosophical Issues in Tourism (ss. 101-116). Bristol: Channel View Pub.

Harari, Y. N. (2015). Sapiens. İstanbul: Kolektif Kitap.

https://www.etymonline.com/word/tour, Erişim tarihi: 03 Ekim 2020.

Kevan, S. M. (1993). Quests for Cures: A History of Tourism for Climate and Health, International Journal of Biometeorol, 37: 113-124.

Kirillova, K., Lehto, X ve Cai, L. (2017). What Triggers Transformative Tourism Experiences?, Tourism Recreation Research, 42 (4): 498-511.

Leiper, N. (1983). An Etymology of “Tourism”, Annals of Tourism Research, 10 (2): 277-280. 
Löschburg, W. (1998). Seyahatin Kültür Tarihi. Ankara: Dost Kitabevi.

McCabe, S. (2009). Who is a Tourist? Conceptual and Theoritical Developments. İçinde: J. Tribe (Ed.). Philosophical Issues in Tourism, (ss.25-42). Bristol: Channel View Pub.

McNeill, W. H. (2019). Dünya Tarihi. Ankara: İmge Kitabevi.

Nash, D. (1981). Tourism as an Antropological Subject, Current Anthropology, 22 (5): 461-481.

Rabotic, B. (2014). Special-Purpose Travel in Ancient Times: "Tourism" before Tourism?. 2nd Belgrade International Tourism Conference (BITCO 2014), (ss. 5-17). Belgrad, Sirbistan.

Robledo, M. A. ve Batle, J. (2017). Transformational Tourism as a Hero's Journey, Current Issues in Tourism, 20 (16): $1736-1748$

Şenel, A. (2006). Kemirgenlerden Sömürgenlere Inssanlık Tarihi. Ankara: İmge Kitabevi.
Şengör, A. M. C. (2017). Teke Tek Özel - 3 Aralık 2017 "Coğrafi Keşifler", https://www.youtube.com/ watch?v=jXiJVqxjGbc, Erişim Tarihi: 29 Ekim 2020.

Towner, J. ve Wall, G. (1991). History and Tourism, Annals of Tourism Research, 18: 71-84.

Watson, P. (2017). Ateşten Freud'a. İstanbul: Yapı Kredi Yayıncllik.

Vukonić, B. (2012). An Outline of the History of Tourism Theory: Source Material (For Future Research). İçinde: C.H.C. Hsu ve W.C. Gartner (Ed.), The Routledge Handbook of Tourism Research (ss. 3-26). Oxon: Routledge.

Dilek ACAR, Doç. Dr., Anadolu Üniversitesi Yunus Emre Kampusu Eskişehir Meslek Yüksekokulu, 26470, Eskişehir

ORCID: 0000-0002-2683-6004

E-posta:dacar1@anadolu.edu.tr 